\title{
KRONİK OBSTRUKTİF AKCİĞER HASTALIĞINA EŞLİK EDEN PNÖMOTORAKSTA OTOLOG KAN İLE PLÖREDEZISS
}

\section{AUTOLOGOUS PLEURODESIS IN PNEUMOTHORAX WHICH DEVELOPED IN CHRONIC OBSTRUCTIVE PULMONARY DISEASE}

\author{
Eray ÇINAR ${ }^{1}$, Kubilay İNAN² ${ }^{2}$ Özgür Ömer YILDIZ ${ }^{3}$
}

\section{ÖZET}

\begin{abstract}
AMAÇ: Plevral aralıkta serbest hava görülmesi olarak tanımlanan pnömotoraksın sekonder sebepleri arasında en sık görülen patoloji Kronik obstruktif akciğer hastalığı (KOAH)'dır. KOAH'lı hastalarda sınırlı pulmoner rezerv nedeniyle pnömotoraks tedavisinin hızlı ve etkin olması önemlidir. Bu çalışmanın amacı, KOAH hastalarında gelişen pnömotoraksta otolog kan ile yapılan plörödezis işleminin sonuçlarını incelemektir.
\end{abstract}

GEREÇ VE YÖNTEM: Kliniğimizde şubat 2017-şubat 2020 yılları arasında KOAH hastalığı olan ve pnömotoraks sebebiyle tüp torakostomi uygulanan ve otolog kan ile plöredezis işlemi yapılan olgular incelendi. Yaş, cinsiyet, sigara öyküsü, plöredezis sonrası semptomlar, nüks oranları, komplikasyon ve hastanede yatış süreleri açısından retrospektif olarak değerlendirildi.

BULGULAR: Yaş ortalaması 65,5 (54-76) olan 27 olgunun tamamı sigara içen erkek hastalardan oluşmaktaydı. Olguların hava kaçağı ortalama süresi 9 (5-16) gün, ortalama yatış süresi 12 gün (819), 3 aylık takiplerindeki nüks oranı ise \%11.1 olarak (3 olgu) bulundu. Olguların hiçbirinde plöredezis sonrası allerjik reaksiyon, enfeksiyon ve ağrı gözlenmedi. 1 olguda $(\% 3,7)$ işlem sonrası cilt altı amfizemi, 5 olguda $(\% 18,5)$ dispne geliști. Olgularda yas arttıkça işlem sonrası saturasyon düşüklüğünün anlamlı olarak arttığı izlendi. Saturasyon değerinin artmasının dispne şikayetini anlamlı şekilde azalttığı, yüksek saturasyon değerlerinin 3 aylık periyotta nüks oranını anlamlı şekilde azalttığı gözlenmektedir $(\mathrm{p}<0,05)$.

SONUÇ: KOAH hastalarında nüksün önlenmesi için yapılan plörödezis işleminin otolog kan ile yapılması, basit ağrısız, maliyet etkin, avantajlı ve etkin bir tedavi yöntemidir.

Anahtar Kelimeler: Sekonder spontan pnömotoraks, KOAH, Plörödezis

\begin{abstract}
AIM: Chronic obstructive pulmonary disease (COPD) is the most common pathology among the causes of secondary pneumothorax defined as free air in the pleural space. It is important that pneumothorax treatment must be fast and effective in patients with COPD due to limited pulmonary reserve. The aim of this study is to examine the results of pleurodesis performed with autologous blood in pneumothorax developing in COPD patients.
\end{abstract}

MATERIAL AND METHOD: Patients with COPD disease who underwent tube thoracostomy due to pneumothorax and pleurodesis with autologous blood between February 2017 and February 2020 in our clinic were analyzed. They were retrospectively evaluated in terms of age, gender, smoking history, symptoms after pleurodesis, recurrence rates, complications, and length of hospital stay.

RESULTS: All 27 patients with a mean age of 65.5 (54-76) were male patients who were smoking. The mean duration of air leak was 9 (5-16) days, the mean hospitalization time was 12 days (8$19)$, and the recurrence rate was $11.1 \%$ (3 cases) in the 3 -month follow-up. None of the cases had allergic reaction, infection or pain after pleurodesis. Subcutaneous emphysema developed in 1 case $(3.7 \%)$, and dyspnea in 5 cases $(18.5 \%)$. As the age of the cases increased, it was observed that the decrease in saturation after the procedure increased significantly. It is observed that the increase in the saturation value significantly reduces the dyspnea complaint, and the high saturation values significantly reduce the recurrence rate in the 3 -month period $(\mathrm{p}<0.05)$.

CONCLUSION: Performing pleurodesis with autologous blood for the prevention of relapse in COPD patients is a simple painless, cost effective, advantageous and effective treatment method.

Keywords: Secondary spontaneous pneumothorax, COPD, Pleurodesis

${ }^{1}$ T.C. Sağlık Bakanlığı, Acil Sağlık Hizmetleri Genel Müdürlüğü, Ankara, Türkiye

${ }^{2}$ Ankara Şehir Hastanesi, Gögüs Cerrahisi Kliniği, Ankara, Türkiye

${ }^{3}$ Yıldırım Beyazıt Üniversitesi, Tıp Fakültesi, Göğüs Cerrahisi AD, Ankara, Türkiye

Geliș Tarihi / Submitted :Kasım 2020 / November 2020

Kabul Tarihi / Accepted : Aralık 2020 / December 2020

Sorumlu Yazar / Corresponding Author:

Özgür ÖMER YILDIZ

Üniversiteler Cad., 1604. Sok. No: 9 Bilkent, Çankaya, Ankara, Türkiye

Gsm: +905338147314 E-posta: dr.ooyildiz@gmail.com
Yazar Bilgileri /Author Information:

Eray CINAR (ORCID: 0000-0002-4564-6097),

Kubilay İNAN (ORCID: 0000-0002-1409-4760) E-posta: kubilay_nan@yahoo.com

Özgür Ömer YILDIZ (ORCID: 0000-0001-7314-3131) E-posta: dr.ooyildiz@gmail.com

Ankara Şehir Hastanesi 1. Nolu Klinik Araştırmalar Etik Kurul Başkanlığı 11/11/2020 tarih ve E1-20-1313 sayı nosu ile etik kurul onayı alınmıştır. 


\section{GİRIŞ}

Spontan pnömotoraks travma ya da herhangi bir girişim olmadan kendiliğinden plevral aralıkta hava toplanmasidır. Primer ve sekonder olarak ikiye ayrilmaktadır. Primer spontan pnomotoraks altta yatan herhangi bir akciğer hastalığının eşlik etmediği daha çok genç bireylerde görülmesine karşın, sekonder spontan pnömotoraks altta yatan akciğer patolojisi olan hastalarda ve ileri yașta görülmektedir $(1,2)$. Sekonder pnomotoraksı birçok hastalık provake etse de Kronik obstruktif akciğer hastalığı (KOAH) en sık görülen sebeptir (3).

KOAH'lı hastalar düşük solunum kapasitesine sahip olduklarından eşlik eden pnömotoraks durumunda mortalite ve morbidite oranları yükselir. Bu nedenle bu durum acil tanı ve tedavi gerektirmektedir $(4,5)$. $\mathrm{KOAH}$ ve pnömotoraksta bir çok tedavi yöntemi tanımlanmış olsa da en sık kullanılan yöntem tüp torakostomidir. Tüp torakostomi sonrası tetrasiklin, talk,bleomisin gibi çeşitli ajanlarla yapılan kimyasal plöredezis tedavide kullanılmaktadır. Çalıșmamızda diğer ajanların aksine lokal ve sistemik yan etkilerinin olmaması ve kullanım ve ulaşım kolaylığı nedeniyle otolog kan ile yaptığımız plöredezis sonuçlarımızı literatür eşliğinde karşılaştırdık.

\section{GEREÇ VE YÖNTEM}

Şubat 2017 ve şubat 2020 tarihleri arasında KOAH olan ve pnömotoraks geliştiği için tüp torakostomi uygulanan ve otolog kan ile plöredezis yapilan $27 \mathrm{olgu}$ retrospektif olarak incelendi. Hastaların dosyaları incelenerek yaşı, cinsiyeti, sigara öyküsü, plörediz işleminin yapıldığ 1 gün, işleme bağlı yan etkiler, komplikasyonlar, erken nüks oranları ve hastanede yatış süreleri veri tabanına kaydedildi. Olgularda tüp torakostomi uygulandiktan 5 gün sonra hava kaçağı miktarına bakılmaksızın ardışık 3 gün süreyle 50 cc otolog kan ile plöredezis işlemi yapıldı. Brakial venlerden alınan 50cc kan toraks dreni ile su altı drenaj sisteminin bağlantı konnektöründen distal geçiş klempe edilerek verildi. Ardından $50 \mathrm{cc} \% 0,9 \mathrm{NaCl}$ solüsyonu gönderilerek plöredezis işlemi uygulandı. Klemplenen line 1 saat kapalı tutuldu. Hastalar yataklarında supin, prone, sol ve sağ lateral dekubit ve trandelenburg posizyonlarına getirilerek kanın plevral yapraklar arasında tam olarak dağılması amaçlandı. Oksijen saturasyon düşüklügüu, ağrı ve dispne olmadıysa ek 1 saat daha tüp bağlantısı yukarı kaldırılarak kanın geri akmasını engelleyecek şekilde klempe edilmeden tutulmuştur. Plöredezis sonrası olgular allerjik reaksiyonlar, ağrı, dispne, oksijen saturasyon seviyeleri, cilt altı amfizem gelişme durumlarına göre tekrar değerlendirlmiştir.

İstatistiksel analizler SPSS for Windows, Version 23.0 (SPSS Inc., Chicago, IL, USA) kullanılarak yapıldı. Sürekli değişkenler ortalama \pm standart sapma olarak kategorik değişkenler ise frekans ve yüzdeler ile sınıflandırıldı. Değişkenler arasındaki ilişkiler ise Pearson Correlation testi ile karşılaştırıldı.
Ankara Şehir Hastanesi 1. Nolu Klinik Araştırmalar Etik Kurul Başkanlığ 11/11/2020 tarih ve E1-20-1313 sayı nosu ile etik kurul onayı alınmıştır.

\section{BULGULAR}

Ortalama yaşları 65 (54-76) olan 27 olgunun tamamı erkek ve sigara içicisi idi. Ortalama 60 paket yıl sigara kullanımı mevcuttu. Başvuru semptomu olarak olguların tamamında (\%100) dispne, 26 olguda pnömotoraks gelişen tarafta ağrı (\%96) bulunmaktaydı. Ortalama hastanede yatış süresi 12 (8-19) gün olarak tespit edildi. Plöredezis sonrası ortalama oksijen saturasyon değeri 90,6 (81-95) olarak belirlendi. Plöredezis sonras1 en s1k görülen semptom dispne $(\% 18,5)$ olup dispne gelişen hastaların ortalama saturasyon değeri 83,6 (8186) olarak tespit edildi. Bu olgular bronkodilatör tedavi ve yüksek nazal oksijen tedavisine cevap verdi.

Olguların hiçbirinde plöredezis sonrası allerjik reaksiyon, enfeksiyon ve ağrı gözlenmedi. 1 olguda $(\% 3,7)$ isslem sonrası 20. dakikada cilt altı amfizemi, 5 olguda $(\% 18,5)$ ilk yarım saatte dispne gelişmiş olup bu olgular dren kelmplenmeden 2 saat deve boynunda takip edildi. Hava kaçağı ortalama süresi 9 (5-16) gün olan olguların ortalama yatış süresi 12 gün (8-19), 3 aylık takiplerindeki nüks oranı ise \%11.1 olarak (3 olgu) bulundu.

Plöredezis işlemi sonrasında oksijen saturasyon düşüklüğü ve dispne şikayeti gelişen olguların ortalama yaş1 70,6 olup, ortalama yatış süresi 14,6 gündür. Oksijen saturasyon düşüklüğü olmayan olguların ise ortalama yaşı 64,4 ortalama yatış süresi ise 11,4 olarak tespit edilmiştir. Saturasyon düzeyi düşük olan olguların yatış gün sürelerinin uzadığ 1 belirlenmiş ancak istatistiksel olarak anlamlı bulunmamıștır. Saturasyon düzeyi ile yaş, dispne, cilt amfizemi geliş̧imi ve nüks arasında da negatif ilişki belirlenmiştir. Bu karşılaştırmalarda saturasyon düzeyi ile yaş, dispne ve 3 aylık kontrollerdeki nüks oranları arasındaki negatif ilișkinin istatistiksel olarak anlamlı olduğu görülmüştür $(\mathrm{p}<0,05)$.

Buna göre; yaş arttıkça saturasyon düşüklüğünün anlamlı olarak fazla izlendiği, saturasyon değerinin artmasının dispne şikayetini anlamlı şekilde azalttığı, yüksek saturasyon değerlerinin 3 aylık periyotta nüks oranını anlamlı şekilde azalttığı gözlenmektedir.

\section{TARTISSMA}

Sekonder spontan pnomotorakslı olgular kadın cinsiyette daha sik bildirilse de sadece KOAH etyolojisi göz önünde bulundurulduğunda, sigara içen erkeklerde daha sık karşılaşılmaktadır $(6,7)$. Bizim de olgularımız tamamı KOAH tanısı almış erkek ve sigara kullanıc1s1 idi. Sekonder pnomotorakslı olgular genellikle orta ve ileri yaş hastalarda görülmektedir. Bizim serimizde de hasta yaşlarının ortalaması 65,5 idi ve literarür ile uyumluydu (8).

Sekonder pnomotorakslı olgularda başvuru semp- 
tomları arasında sırt ağrısı ve dispne görülmektedir. Dispne bulgusu, solunum seslerinde hafif azalmadan, ciddi solunum yetmezliğine kadar değișebilen aralıkta olabilmektedir (5). Olgularımızın başvuru semptomları arasında dispne (\%100) ve ilgili hemitoraksta gögüs ağrısı (\%96) oranındaydı.

Bizim olgularımızda ortalama hava kaçağı süresi 9 (516) gün olarak bulundu. Türkyılmaz ve arkadaşlarının yaptığ bir çalışmada da benzer olarak sadece göğüs tüpü takılarak veya göğüs tüpü yoluyla plöredezis uygulanarak tedavi edilen hastalarda drenaj süresi ortalama 10,0 99,9 gün (1-65 gün) idi (4). Bazı yazarlar, hasta yatış süresinin uzaması ve tedavi maliyetindeki artış nedeniyle ilk atakta dahi uzamış hava kaçağında cerrahi tedaviyi önermektedirler (9). Pnomotoraksta tüp torakostomi ve tekrarlayan plöredezisler ile birçok vakanın cerrahisiz olarak tedavi edebileceğini, KOAH olgularında yaygın amfizem nedeniyle cerrahi tedavi ile morbidite ve mortalitenin artabileceğini düşünüyoruz.

Plöredezis için en sık kullanılan ajanlar olan tetrasiklin ve talkın yan etkileri bildirilmiştir. KOAH'lı hastalar düşük solunum kapasitesine sahip olduklarından bu yan etkileri tolere etmekte oldukça sıkıntı yaşarlar. $\mathrm{Bu}$ nedenle KOAH hastalarında daha az yan etkiye sahip otolog kan ile plöredezis düşük nüks ve yan etki oranları ile güvenle uygulanabilmektedir (4).

Sekonder pnomotoraksta altta yatan akciğer hastalığı ve ileri yaşa bağlı olarak rekürrens oranları daha yüksektir ve \%43 olarak bildirilmektedir (10). KOAH'l hastalarda her pnömotoraks atağının mortaliteyi 4 kat artırabileceği bildirilmiștir (5). Bu nedenle nüksün önlenmesi oldukça önemlidir. KOAH'lı hastalarda gelişen pnömotoraks tedavisinde plöredezis yapılmaz ise hastaların \%40-50 sinde tekrar pnömotoraks görülebilmektedir (11). Sekonder pnomotorakslı olgularda klinik, primer spontan pnomotoraksa göre daha kötü seyretmektedir ve basit aspirasyonla başarı şansı oldukça düşüktür (\% 37’ye karşıllk \% 75) (12). Bu nedenle "ACCP" (American Collage of Chest Physicians) klavuzunda bu tür hastalarla karşılaşıldığında tüp torakostomi uygulanmasinı ve rekürrensi önlemek için plörodezis yapılmasını önermektedirler (13). Tokat ve arkadaşlarının çalışmasında KOAH'lı hastalardaki nüks oranlarını $\% 27$ olarak bildirmişlerdir $(\mathrm{H})$. Bizim 27 hastamızın 3' ünde erken nüks görülmüş olup oranı $\% 11,1$ olarak bulunmuştur.

\section{SONUÇ}

Plöredezis işlemi, KOAH hastalarında gelişen pnömotoraksta tüp torakostomiye ek tedavi basamağ nüks oranlarını azaltılmak için gögüs cerrahları tarafindan tercih edilen bir uygulamadır. Bu işlemin otolog kan ile yapılması basit, kolay uygulanabilir, kolay erişilebilir, ağrısız, maliyet etkin ve avantajlı olması tercih edilebilirliğini arttırmaktadır.

Conflict of interests: The authors declare no conflict of interests. Funding: There is no financial support.

\section{KAYNAKLAR}

1.)Schramel FM, Postmus PE, Vanderschueren RG. Current aspects of spontaneous pneumothorax. Eur Respir J. 1997;10:1372-9.

https://doi: 10.1183/09031936.97.10061372.

2.)Henry M, Arnold T and Harvey J. BTS guidelines for the management of spontaneous pnuemothorax. Thorax 2003;58:39-52. https://doi: 10.1136/thorax.58.suppl_2.ii39.

3.)Çelik B, Nadir A, Şahin E, et al. Nüks spontan pnömotrakslı olgularda risk faktörleri, klinik ve radyolojik değerlendirme.Türk Göğüs Kalp Damar Cer Derg; 2008;16:107-12.

4.) Türkyılmaz A, Erdem AF, Aydın Y, et al. Treatment of Secondary Spontaneous Pneumothorax: 100-Patient Experience. Eurasian J Med. 2007;39:97-102.

5.)Williams-Johnson J, Williams EW, Hart N, et al. Simultaneous spontaneous bilateral pneumothoraces in an asthmatic. West IndianMed J. 2008;57:508-10.

6.)Gök M, Ceran S, Sunam G ve ark. Spontan pnömotorakslı kadın olguların değerlendirilmesi. Tip Araştırma Der 2007; 5: 27-30.

7.)Light RW. Manegement of spontaneous pneumothorax. Am Rev Respir Dis 1993;148:245-8. https://doi.org/10.1164/ajrccm/148.1.245. 8.)Kuzucu A, Soysal O, Ulutaş H. Optimal timing for surgical treatment to prevent recurrens of spontaneous pneumothorax. Surg Today 2006;36:865-68. https://doi.org/10.1007/s00595-006-3263-0 9.)Kuzucu A, SoysalÖ, Ulutaș H. Spontan Pnömotoraksta Rekurrens ve Cerrahi Tedavide Zamanlama. Inönü Üni Tip Fak Der 2005;12:16972. 10.)Light RW, O'Hara VS, Moritz TE, et al. Intrapleural tetracycline for the prevention of recurrent spontaneous pneumothorax. Results of a department of veterans affairs cooperative study. JAMA 1990;264:2224-30.

11.)Tokat AO, Karasu S, Özkan M, Kısacık E, Çakmak H. Sekonder Spontan Pnömotoraks: Etyoloji ve Tedavi Yöntemleri Ankara Üniversitesi Tip Fakültesi Mecmuası 2010;63:111-3.

https://doi.org/ 10.1501/Tipfak_000000773

12.)Baumann MH, Strange C: Treatment of spontaneous pneumothorax: A more aggresive approach? Chest 1997;112:789-804. https://doi.org/10.1378/chest.112.3.789.

13.)Baumann $M H$, Strange $C$, Heffner JE, et al. Management of spontaneous pneumothorax: an American College of Chest Physicians Delphi consensus statement. Chest 2001; 119: 590-602. https://doi.org/10.1378/chest.119.2.590.

Ankara Eğt. Arş. Hast. Derg. (Med. J. Ankara Tr. Res. Hosp.), 2020 ; 53(3) : 206-208

Ankara Şehir Hastanesi 1. Nolu Klinik Araștırmalar Etik Kurul Başkanlığı 11/11/2020 tarih ve E1-20-1313 sayı nosu ile etik kurul onayı alınmıştır. 